\title{
Psycho-Biological Factors of the Formation of Killer Teenagers and Their Prevention
}

\author{
Nugzar Aleksidze* \\ Department of Pshycology, Georgia \\ *Corresponding author: Nugzar Aleksidze, Department of Pshycology, Georgia.
}

\begin{abstract}
The psychobiological factors of the formation of killer teenagers have been investigated. It was established that the neurobiological correlate of aggressive killer organisms is serotonin. Its content in the brain of killer organisms is about $50 \%$ lower compared to normal ones. Psychobiological factors of the prevention of killer organisms' formation, comprising adequate nutrition and physical exercises have been demonstrated.
\end{abstract}

Keywords: Killer Organisms; Serotonin; Triptophan

\section{Introduction}

During last period confrontation between 14-16 years old teenagers resulting in murder, became very frequent. There may be given many examples of tragedies which happened in different countries, when young people have died of multiple wounds. Parents, teachers, representatives of police, school supervisors, psychologists hold active debates by TV-shows and radio transmissions about the necessity to increase vigilance and activity, to conduct additional trainings for supervisors; but nobody asks what is the reason for such cruel behavior among the youth. Several psycho-emotional factors, responsible for the formation of aggressive and killer organisms have been distinguished during our multiyear neurochemical studies [1,2]. These are: 1 . the aggressive social surrounding in the family; 2 . wrong diet; 3 . increased level of sex-hormones (testosterone) in 14-16 years old boy-teenagers; 4. existence of "war" and "murder" genes, caused by chromosomal disorders; and 5. TV transmissions, demonstrating and favoring killing, speculating for the emphatic appreciation of the information by young people.

Since the Italian neurobiologist Giacomo Rizzolatti has discovered mirror neurons in brain, responsible for perception of speech and behavior of surrounding people by a newborn, it becomes clear that if the post natal development of a newborn takes place in an aggressive social surrounding (fight between family members, violence, usage of narcotics, alcohol), the aggressive behavior will be encoded in his genetic apparatus. This information stays in the organism of a person during the whole life and may be revealed in the form of aggressive behavior of a young person [1,2]. Incomplete nutrition is the second factor for murder. We have established that the biogenic amine serotonin is one of the neurobiological correlates for the formation of aggressive and killer organisms. Its deficiency in young organisms may become reason for aggressive behavior and killing [3-8]. Experimentally it was demonstrated that feeding of experimental rats with tryptophanpoor food during 10-12 days, which is the precursor of serotonin, caused decrease of serotonin content for $50 \%$ in experimental animals. As a result these organisms turned into killers. If the diet was enriched with tryptophan $(100 \mathrm{mg})$, rat-killers turned into peaceful ones, tolerant to frogs and mice. Diversely from normal rats not a single case of murder was mentioned during contact with them. It must be taken into account that in aggressive to animals children content of serotonin, as a rule, is essentially low, as well as in those monkeys, who have lost the leader's function in their group. Accordingly, the behavior of prestige-lost children must be observed attentively at school $[4,5]$.

For the prevention purposes supplying school buffets with cheeseburgers, prepared of tryptophan-rich Dutch and melted cheese, which is the precursor of serotonin, is desirable. $100 \mathrm{~g}$ of Dutch or melted cheese contains 790 and $500 \mathrm{~g}$ of tryptophan respectively. This amount of the substance is able to raise the 
content of serotonin in a young organism and essentially decrease his aggressive behavior. It is well known that isolation from the society is one additional powerful factor for the formation of an aggressive person. That's why the single-child families must take care for social formation of a child with friends in kinder-gardens, to prevent aggression [6].

14-16 years is the crucial age for teenagers and serious changes are mentioned in male hormonal balance at this period. Special experiments were conducted on animals to reveal the relationship between aggression and murder and changes of masculine sexhormones. The experimental rats were castrated. As a result no cases of aggression or killing have been revealed from castrated animals towards mice and frogs. While injection of test animals with testosterone changed the situation in the opposite directioncases of mice and frogs killing by rats became evident. For the prevention the facts of killing the fatigue tests using swimming has been done with experimental rats. The result was interesting: killer rats became again tolerant toward mice and frogs and no case of aggression or murder has been revealed $[6,8,9]$.

Accordingly, our recommendation to school supervisors is to increase the physical activity between-lessons of teenagers for diminishing the content of biologically active compounds in blood, among them of sex-hormones. We hope that the government will try all the best to improve the situation to the direction of aggression elimination and healthy life-style introduction $[10,11]$

Unfortunately existence of "war" and "murder" genes in sexchromosomes is reality. According to experimental data four groups of aggressive and criminal behavior persons are distinguished:

a) young men with Klinfelter syndrome. They have XXYY set of sex-chromosomes, small testicles, are taller than average; due to mental deficiency it is easy to involve them in criminal.

b) Young males with aberrant XYY or XXYY sex-chromosomes They are tall, with mental deficiency, are distinguished with aggression and criminal activity.

c) Young men with hereditary disorder of nervous system They are distinguished with emotional-ethic degradation, epileptic anxiety, dogmatism, schizoid personality and alcoholinduced disorders.

This work is licensed under Creative Commons Attribution 4.0 License

To Submit Your Article Click Here: Submit Article

DOI: $10.32474 /$ SJPBS.2019.02.000133 d) 1/4 of the single-egg twins are inclined to criminal activity. These children must be under the permanent observation of psychologists for evaluation of their behavior.

All above mentioned indicates that school psychologist have to know deeply the genetic picture of each school-boy, to forecast their future behavior and prevent possible criminal prevention $[3,5,6]$.

\section{Conclusion}

Psycho-social factors of murder formation have been established. It was demonstrated that one of the neural correlates in killer's brain is serotonin, which content is by $50 \%$ lower in brains of aggressive killer organisms. The ways of prevention of aggressive behavior by adequate diet and physical activity is offered.

\section{References}

1. Aleksidze N (2007) Neurochemical basis of the stress, aggression and formation of killer rats. Act. prob. in neurochemistry and neuroimmunology. The Int Symp Yerevan Armenia p. 24-26.

2. Aleksidze N (2007) Chronic Sress and Pathological Aggression as Premise for Killer Rats Formation. Bull. Georgian Nat Acad Sci 175(2): $81-85$

3. N Aleksidze (2014) Lectures in psychology for students of psychology. The Georgian University of Andrew the First-called, Georgian.

4. Aleksidze N (2011) Aggressive social environment, stress, depression and formation of killer organisms. Meeting of the Society of Applied Neurosciences, Thessaloniki, Greece 125: 5-8.

5. Aleksidze N (2014) Basics of psychobiology. Georgian Acad. Sci. in Georgian.

6. Aleksidze N (2017) Psycho-biological basis of killers and self-killers formation. SakResp. Georgian P.

7. Aleksidze N, Goguagze R, Micaville N, Chischilly M (1996) Comparative analysis of Biogenic amines distribution in white rat brain at different forms of aggression. Bulletin of the Georgian 2: 293-296.

8. Aleksidze N, Goguadze R, Chachua M (2004) The relationship between chronic stress, aggression and murder. Proc Georg Acad Sci Biol Series A 30(6): 781-785

9. Aleksidze N (2013) Serotonin and sex hormones participation in the formation of killer rats. Neurochemistry 30(4): 101-104.

10. Goguadze RP, Chachua ND, Kiburiya ND, Chapmanville MD, Aleksidze Gian, et al. (2006) Changes in the surface of erythrocyte membrane during chronic stress in rats. Bulletin of experimental biology and medicine 141(5): 581-583.

11. Aleksidze N, Tanseli N (2015) lnfluence of Environmental and Social Stress Factors on Distribution of Serotonin in the Brain and Development of Killer and Self-Killer Organisms. New Developments in Serotonin Research Editor: Ming D Li, Nova Science Publisher P. 51-65.

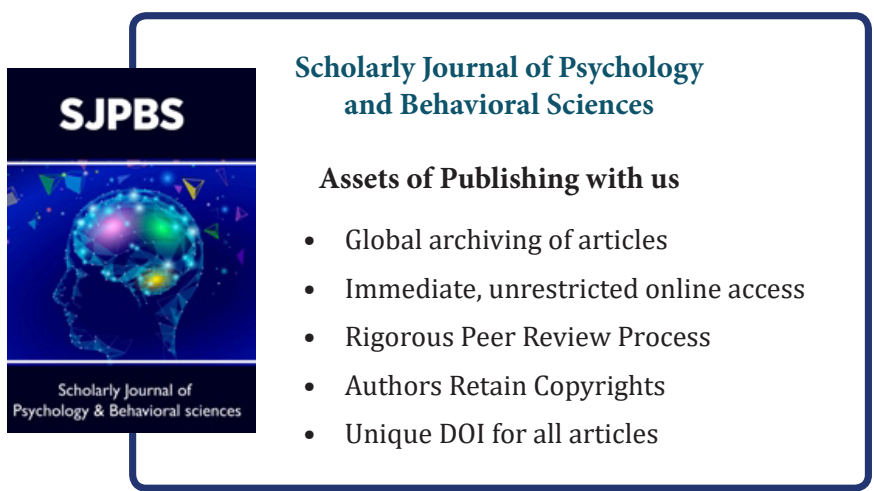

